\title{
Comparative fine mapping of fruit quality QTLs on chromosome 4 introgressions derived from two wild tomato species
}

\author{
Heather E. Yates ${ }^{1}$, Anne Frary ${ }^{1,3}$, Sami Doganlar ${ }^{1,3}$, Anna Frampton ${ }^{2}$, Nancy T. Eannetta ${ }^{1}$, \\ John Uhlig ${ }^{2} \&$ Steven D. Tanksley ${ }^{1}$ \\ ${ }^{1}$ Department of Plant Breeding, 245 Emerson Hall, Cornell University, Ithaca, NY 14853, U.S.A.; ${ }^{2}$ Seminis Ve- \\ getable Seeds, 37537 State Highway 16, Woodland, CA 95659, U.S.A.; ${ }^{3}$ Present address: Department of Biology, \\ Izmir Institute of Technology, Gulbahçe Campus, Urla 35437, Izmir, Turkey
}

Received 14 May 2003; accepted 2 September 2003

Key words: L. esculentum, L. hirsutum, L. peruvianum, soluble solids, wild germplasm

\begin{abstract}
Summary
Despite their unsuitability for agricultural production, the wild relatives of crop species represent a largely untapped resource of novel QTLs potentially useful for crop plant improvement. In this regard, previous introgression studies, involving several different wild tomato species, have shown that the long arm of chromosome 4 contains QTLs for many horticulturally important traits including soluble solids content, fruit shape, lycopene content and biochemical composition. However, these earlier studies were unable to determine how many genes control these traits and whether genes affecting the same character from different wild species are allelic or not. In an effort to shed light on these issues, we have constructed a series of lines containing small, overlapping introgressions for portions of the long arm of chromosome 4 from L. peruvianum and L. hirsutum and tested these lines in replicated field trials. The results provide evidence for multiple, non-allelic loci controlling soluble solids and fruit weight. They also show that the loci controlling some traits (e.g. fruit shape, fruit weight, epidermal reticulation) co-localize to the same portions of chromosome 4, a result that may be attributed to pleiotropy and/or gene dense areas with lower than average recombination. The implications of these finding for molecular breeding and utilization of exotic germplasm are discussed.
\end{abstract}

\section{Introduction}

Reduced levels of genetic variation can be seen in cultivated varieties compared with their wild relatives, and this is especially true for self-pollinated crops (Miller \& Tanksley, 1990; Tanksley \& McCouch, 1997). One way to increase genetic variation and potentially boost performance of crop varieties is by tapping into the vast reservoir of novel alleles found in wild germplasm (Tanksley \& McCouch, 1997). The wild relatives of crop species often carry hidden alleles, which may not be phenotypically obvious, yet which can be effectively introduced into elite cultivars for improved performance (de Vincente \& Tanksley, 1993; Foolad et al., 2002; Fulton et al., 2000). In previous work on tomato, the introduction of small segments of DNA from a wild species has been shown to enhance favorable traits such as soluble solids, yield, early fruit ripening, color, and viscosity (Frary et al., 2002; Fulton et al., 2000; Eshed \& Zamir, 1995). This process is facilitated by using advanced backcross populations to detect QTLs in an elite cultivar's genetic background (Tanksley \& Nelson, 1996).

While advanced backcross populations and near isogenic lines (NILs) can be used to discover and verify potentially valuable QTLs from exotic germplasm, follow-up work is often necessary to localize the genetic locus (or loci) underlying a QTL more precisely and to reduce or mitigate linkage drag and facilitate marker assisted selection (MAS). In a recent study, it was possible to use a series of subNILs for chromosome 1 to fine map the loci controlling a number of valuable QTLs for soluble solids and other 
traits important to processing tomato varieties (Frary et al., 2002). For the current study, we have employed a similar strategy to fine map QTLs from wild tomato species on the long arm of chromosome 4. In independent studies utilizing different wild donor species, a variety of beneficial QTLs affecting fructose to glucose ratio (Levin et al., 2000), fruit color, soluble solids content (Bernacchi et al., 1998b; Fulton et al., 2000; Monforte et al., 2001), epidermal reticulation, fruit shape (Fulton et al., 2000; Monforte et al., 2001), and acid content (Fulton et al., 2000) have been mapped to this region of the genome.

To fine map QTLs on chromosome 4 we have generated two sets of subNILs, containing overlapping introgressed segments for the bottom of this chromosome from L. hirsutum LA1777 (Bernacchi et al., 1998a) and L. peruvianum LA1708 (Fulton et al., 1997b). All subNILs were created in the same $L$. esculentum cv E6203 (TA209) recurrent parent background to allow comparison amongst subNILs derived from the same species as well as subNILs derived from different species.

\section{Materials and methods}

\section{Original introgression lines}

TA 1138 is a NIL containing a $47 \mathrm{cM}$ segment (from TG62 to CP57) of the lower portion of the long arm of chromosome 4 (Figure 1). This NIL was obtained by backcrossing L. hirsutum (LA 1777) to L. esculentum cv E6203 combined with marker assisted selection (Bernacchi et al., 1998a). TA1160 is a NIL that contains a $19 \mathrm{cM}$ segment (from CT50 to TG587) on the lower portion of chromosome 4 (Figure 1). This NIL was derived from an advanced backcross of $L$. esculentum cv E6203 × L. peruvianum LA1708 combined with marker assisted selection (Fulton et al., 1997a).

\section{Development of subNILs}

TA1138 subNILs: In order to fine map the QTLs within the introgression, as well as to determine which QTLs are controlled by linked loci and which may be due to a single locus with pleiotropic effects, a series of subNILs was developed for each of the NILs described above. A total of $705 \mathrm{~F}_{2}$ plants were derived from a cross between $L$. esculentum cv E6203+Tm2a resistance (here in referred to as TA496) $\times$ TA1138. DNA was extracted from each individual and screened for the flanking ends of the introgression with markers
TG65 and TG500. This screen resulted in the isolation of 76 recombinant individuals in the interval. More DNA was collected from these recombinants, and the point of recombination was determined by screening 15 markers located within the introgression (Figure 1). These recombinants fell into 17 different classes when categorized by their point of recombination (Figure 2). $\mathrm{F}_{3}$ individuals derived from each recombinant line were then screened with TG65, T861, and $\operatorname{Tm} 2 a$, and homozygous recombinant lines were selected. When possible a $\operatorname{Tm} 2 a$ resistant line and a $\operatorname{Tm} 2 a$ susceptible line were retained, although only those that were $\operatorname{Tm} 2 a$ susceptible were evaluated in the current study to ensure consistency with the recurrent parent ( $L$. esculentum cv E6203) background for the subNILs derived from TA1160 (see below). F3 homozygous lines were selfed for $\mathrm{F}_{4}$ seed increase. A molecular linkage map for the bottom of chromosome 4 was generated from the TA1138 $\times$ TA209 $\mathrm{F}_{2}$ population using Mapmaker 2.0 (Lander et al., 1987) (Figure 1). The Kosambi mapping function was used to convert recombination frequencies to map distances in centiMorgans (cM) (Kosambi, 1944). The length of the introgressed segment was measured at $47 \mathrm{cM}$ which is approximately the same as the $48 \mathrm{cM}$ reported for the L. esculentum $\times$ L. pennellii $\mathrm{F}_{2}$ (Tanksley et al., 1992).

TA1160 subNILs: A total of $1088 \mathrm{~F}_{2}$ plants were derived from a cross between L. esculentum cv E6203 (here in referred to as TA209) $\times$ TA1160 and screened with the markers that flanked the ends of the introgression, TG50 and TG587. This resulted in the isolation of 192 recombinant individuals. These recombinants were further screened with six markers located within the introgression (Figure 1). Recombinants fell into 8 different classes when categorized by their point of recombination (Figure 3 ). $\mathrm{F}_{3}$ individuals of 42 recombinant lines were again screened with markers TG50 and TG587, the homozygous lines were retained, and $\mathrm{F}_{4}$ seed was generated. A molecular linkage map for the bottom of chromosome 4 was generated from the TA1160 × TA209 $\mathrm{F}_{2}$ population as described above. The length of the introgressed segment was measured at $19 \mathrm{cM}$, which is less than the $26 \mathrm{cM}$ reported for the L. esculentum $\times$ L. pennellii $\mathrm{F}_{2}$ (Tanksley et al., 1992).

\section{Field evaluations}

TA1138 and TA1160 subNILs were evaluated in the field at two locations: Woodland, CA and Ithaca, 


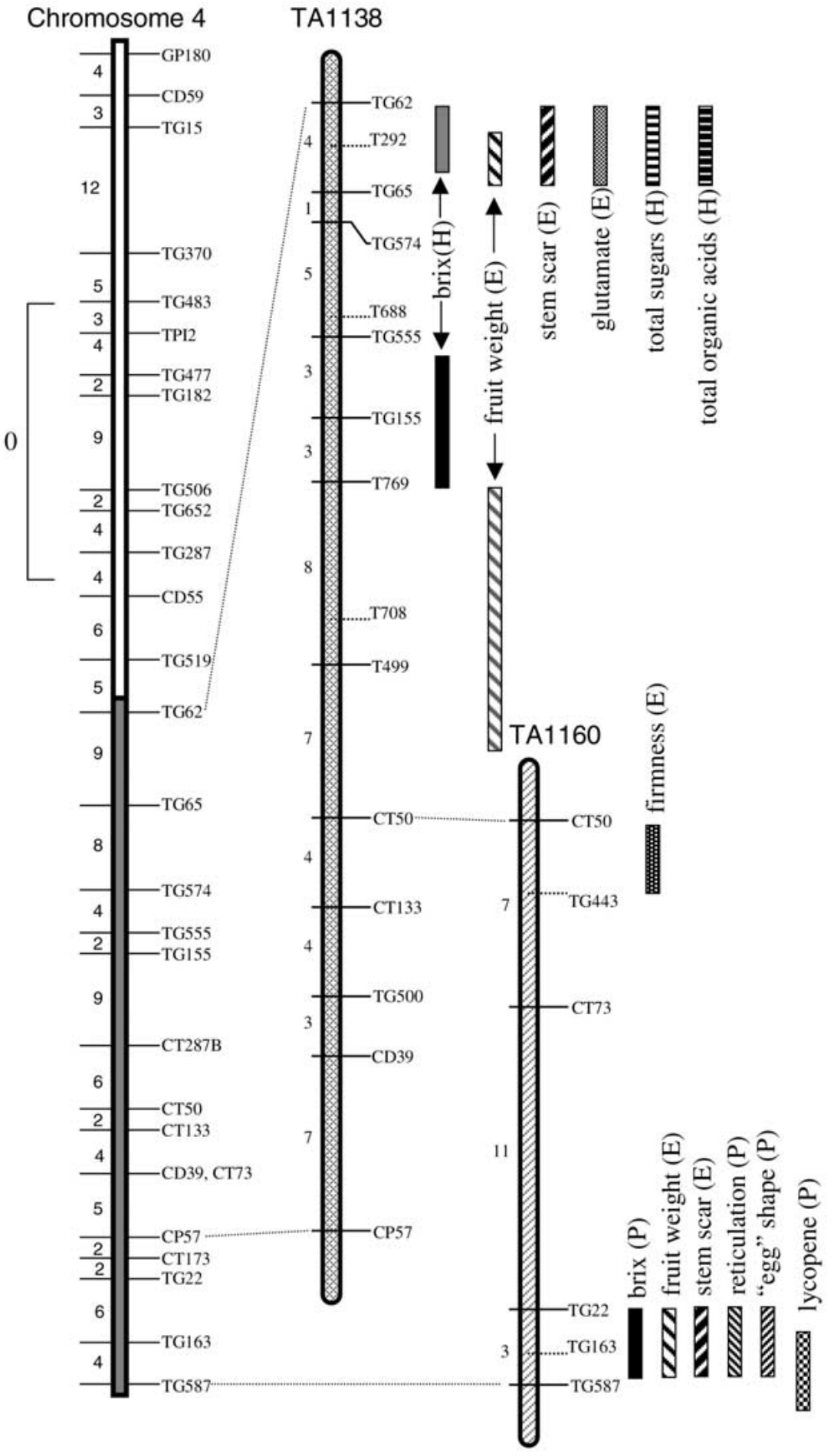

Figure 1. Comparison of chromosome 4 linkage maps for the L. esculentum $\times$ L. pennellii (Tanksley et al., 1992), TA1138 $\times$ TA209, and TA1160 $\times$ TA209 $\mathrm{F}_{2}$ populations, as well as the QTLs discerned by these studies. The shaded region shows the extent of the introgression in both TA1138 and TA1160. The approximate position of the centromere is also indicated in brackets. Primary QTLs are shown in black, secondary QTLs are shown in gray where applicable. 


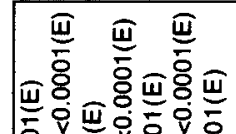

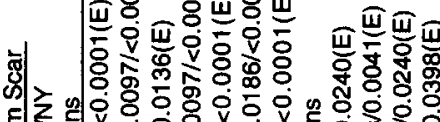

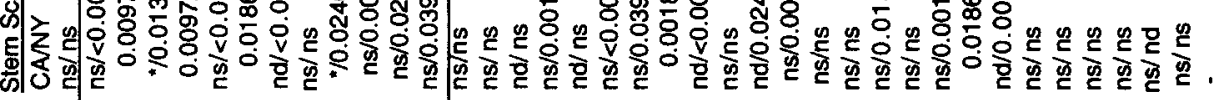

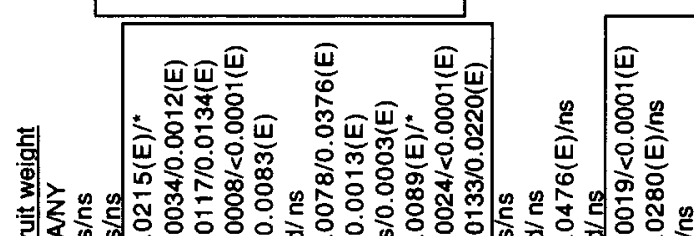

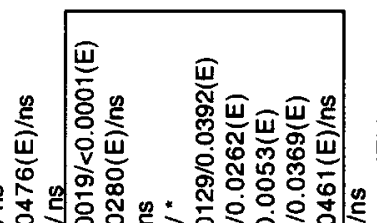

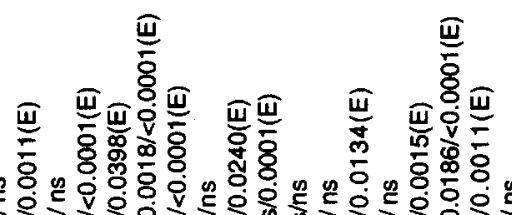

崖

音

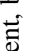

ठ․․

要要,

를 뫃

을

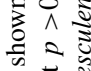

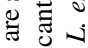

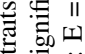

焉

至

尝

…

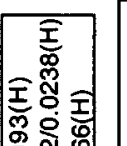

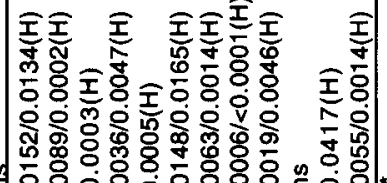

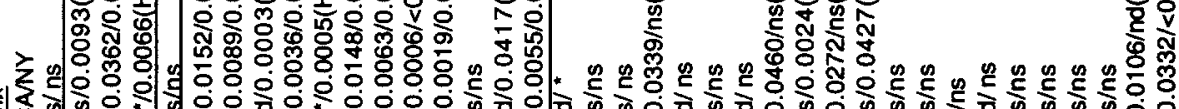

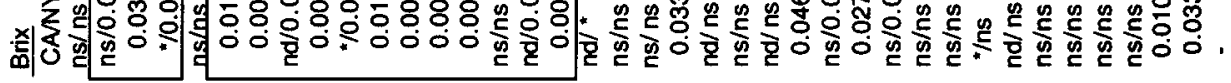

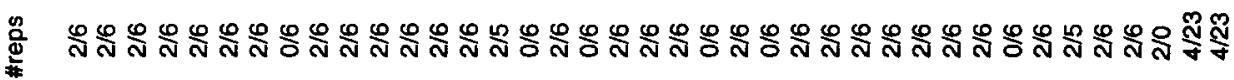
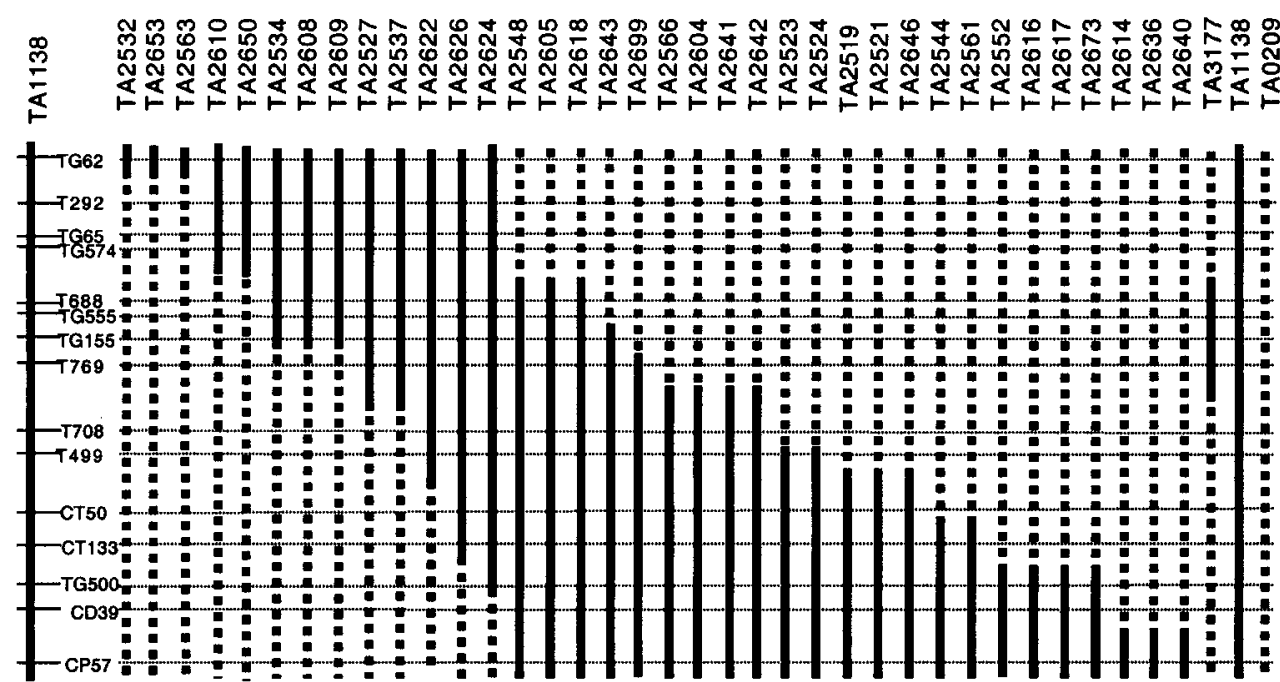


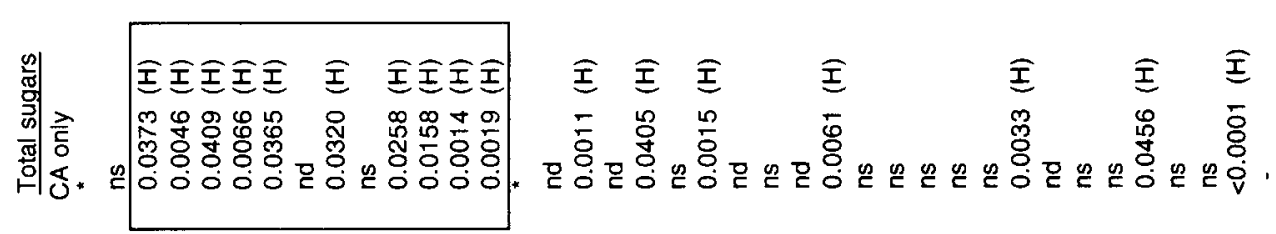

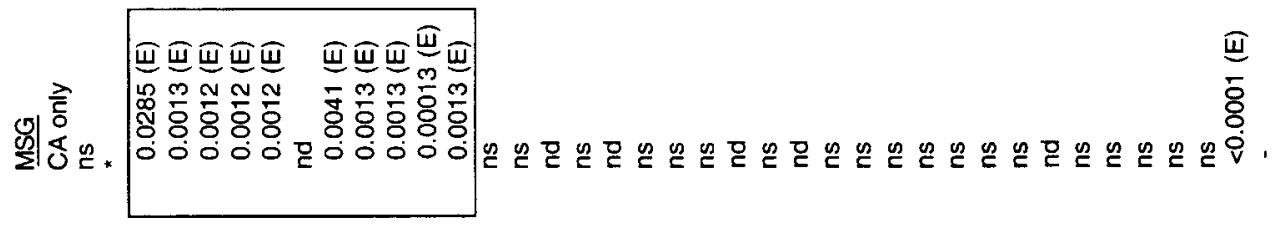

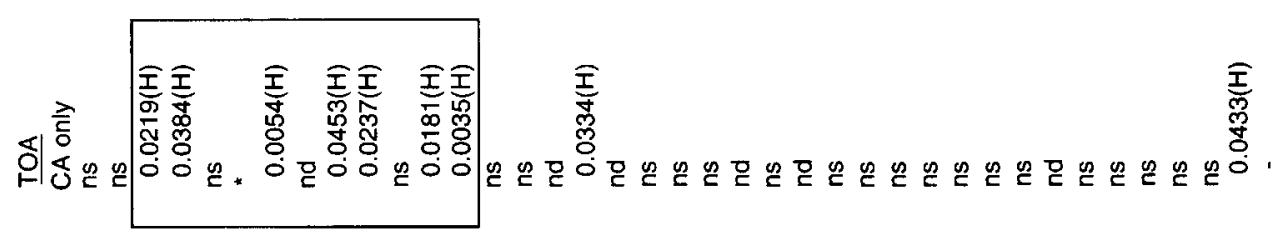

5
0
0
0

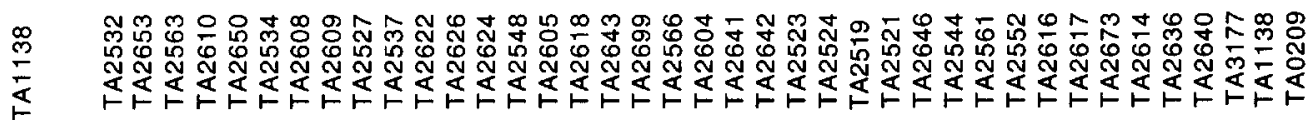

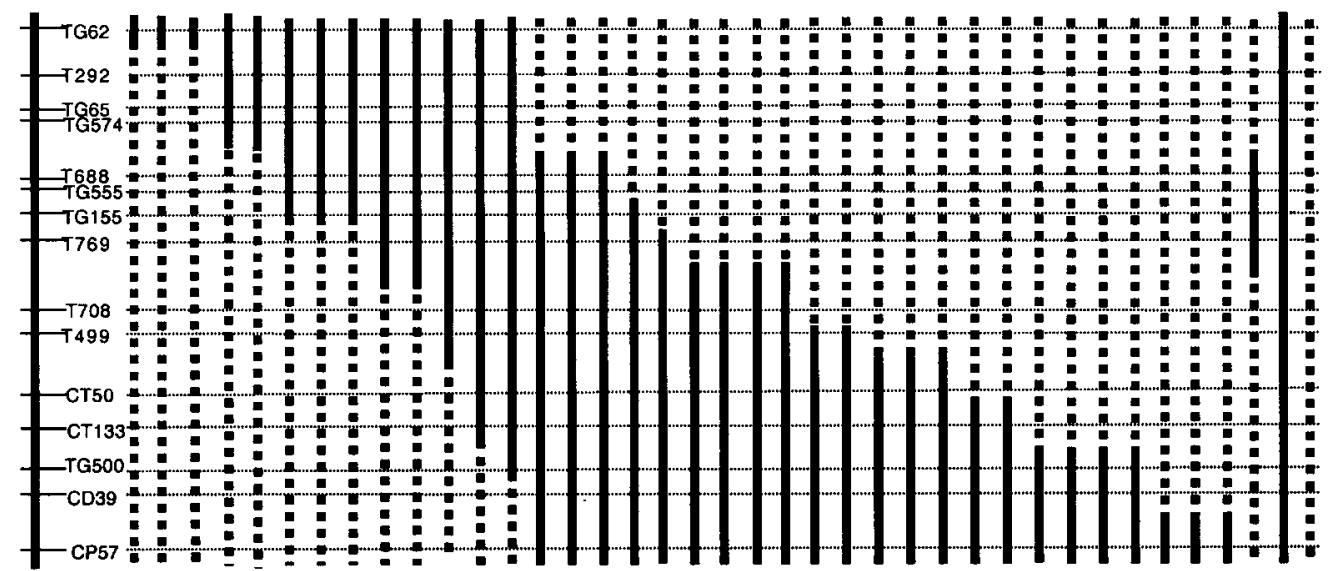

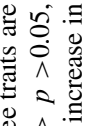

这을

它家

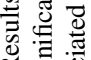

悹 
Table 1. Means and standard deviations of quantitative traits for TA1138 and TA209-traits with asterisks $\left(^{*}\right)$ are significantly different (p-value $>0.05)$

\begin{tabular}{|c|c|c|c|c|c|c|c|c|c|}
\hline \multirow[t]{3}{*}{ Category } & \multirow{3}{*}{$\begin{array}{l}\text { Trait } \\
\text { measured }\end{array}$} & \multicolumn{4}{|c|}{ New York } & \multicolumn{4}{|c|}{ California } \\
\hline & & \multicolumn{2}{|c|}{ TA209 } & \multicolumn{2}{|c|}{ TA1138 } & \multicolumn{2}{|c|}{ TA209 } & \multicolumn{2}{|l|}{ TA1138 } \\
\hline & & Mean & st dev & Mean & st dev & Mean & $\overline{\text { st dev }}$ & Mean & st dev \\
\hline \multirow[t]{6}{*}{ Fruit color } & External color & $6.2^{*}$ & 0.8 & $7.1^{*}$ & 1.1 & 6.0 & 0.8 & 6.0 & 1.2 \\
\hline & Internal color & 7.0 & 1.0 & 7.2 & 1.0 & 5.5 & 0.6 & 6.0 & 0.8 \\
\hline & Lycopene & nd & nd & nd & nd & 94.9 & 16.0 & 102.9 & 4.9 \\
\hline & Hue & nd & nd & nd & nd & 23.9 & 1.5 & 22.5 & 1.4 \\
\hline & Chroma & nd & nd & nd & nd & 16.0 & 0.8 & 16.7 & 1.0 \\
\hline & $\mathrm{A} / \mathrm{b}$ & nd & nd & nd & nd & 2.3 & 0.2 & 2.4 & 0.2 \\
\hline \multirow[t]{8}{*}{ Fruit quality } & Fruit weight & $85.7^{*}$ & 11.0 & $69.3^{*}$ & 9.2 & $90.5^{*}$ & 5.2 & $58.3^{*}$ & 9.6 \\
\hline & Stem scar & $5.7^{*}$ & 0.6 & $4.8^{*}$ & 0.9 & 5.8 & 0.5 & 4.8 & 1.3 \\
\hline & Cracks & 2.9 & 1.1 & 2.5 & 0.9 & 4.3 & 1.5 & 3.5 & 1.0 \\
\hline & Firmness & $6.3^{*}$ & 0.6 & $7.4^{*}$ & 0.6 & 5.5 & 1.3 & 4.8 & 1.0 \\
\hline & Reticulation & 1.0 & 0.5 & 1.3 & 0.5 & nd & nd & nd & nd \\
\hline & 'dull' & nd & nd & nd & nd & $2.3^{*}$ & 0.5 & $5.0^{*}$ & 0.8 \\
\hline & Wall & 7.4 & 0.7 & 7.7 & 0.6 & 5.0 & 0.8 & 4.8 & 0.5 \\
\hline & Puffy & 1.6 & 0.8 & 1.4 & 0.5 & 4.8 & 1.5 & 3.8 & 1.0 \\
\hline \multirow[t]{14}{*}{ Processing quality } & Brix & $5.1^{*}$ & 0.4 & $6.1^{*}$ & 0.7 & $4.7^{*}$ & 0.2 & $5.1^{*}$ & 0.3 \\
\hline & Glutamate & nd & nd & nd & nd & $22.5^{*}$ & 3.3 & $2.8^{*}$ & 1.2 \\
\hline & Sucrose & nd & nd & nd & nd & 0.1 & 0.0 & 0.2 & 0.1 \\
\hline & Glucose & nd & nd & nd & nd & $0.8^{*}$ & 0.1 & $1.2^{*}$ & 0.0 \\
\hline & Fructose & nd & nd & nd & nd & $1.1^{*}$ & 0.1 & $1.6^{*}$ & 0.0 \\
\hline & Total sugars & nd & nd & nd & nd & $2.0^{*}$ & 0.2 & $3.1^{*}$ & 0.1 \\
\hline & Vitamin A & nd & nd & nd & nd & 2.3 & 0.7 & 2.9 & 0.8 \\
\hline & Beta-Carotene & nd & nd & nd & nd & 1.4 & 0.2 & 1.4 & 0.5 \\
\hline & $\mathrm{pH}$ & nd & nd & nd & nd & 4.3 & 0.1 & 4.2 & 0.2 \\
\hline & Total organic acids (TOA) & nd & nd & nd & nd & $21.4^{*}$ & 2.3 & $28.8^{*}$ & 5.3 \\
\hline & TA & nd & nd & nd & nd & $4.6^{*}$ & 0.4 & $6.1^{*}$ & 0.8 \\
\hline & Sugar/acid ratio (SAR) & nd & nd & nd & nd & $5.7^{*}$ & 0.5 & $4.7^{*}$ & 0.4 \\
\hline & Juice Bostwick & nd & nd & nd & nd & $18.8^{*}$ & 1.9 & $13.9^{*}$ & 0.9 \\
\hline & Ostwald & nd & nd & nd & nd & $242.7^{*}$ & 20.8 & $972.9^{*}$ & 220.5 \\
\hline \multirow[t]{7}{*}{ Agronomic quality } & yield potential & nd & nd & nd & nd & 4.5 & 1.0 & 5.0 & 2.8 \\
\hline & lstred & nd & nd & nd & nd & 35.5 & 5.2 & 37.3 & 4.3 \\
\hline & $\%$ red & nd & nd & nd & nd & 82.5 & 9.6 & 78.8 & 14.4 \\
\hline & $\%$ stem & nd & nd & nd & nd & 20.5 & 21.0 & 18.8 & 14.9 \\
\hline & Fruit uniformity & nd & nd & nd & nd & $4.0^{*}$ & 0.0 & $6.3^{*}$ & 1.7 \\
\hline & cover & nd & nd & nd & nd & $4.3^{*}$ & 1.0 & $6.0^{*}$ & 0.8 \\
\hline & Yield lb/4 & nd & nd & nd & nd & 32.3 & 2.3 & 29.3 & 6.2 \\
\hline
\end{tabular}

NY. In California (CA), a subset of 54 homozygous TA1138 subNIL lines and 3 controls (TA209, TA496, and TA1138) were transplanted to the field in April 2002 in plots of 15 plants each, with two replications per location at two locations. A subset of 40 homozygous TA1160 subNIL lines and the 2 controls (TA209, TA1160) were transplanted to the field in April 2001 in plots of 15 plants each, with three replications per location at two locations. In New York (NY), a subset of 67 homozygous TA1138 subNIL lines and 3 controls (TA209, TA496, and TA1138) were transplanted to the field on May 30, 2002. A subset of 35 homozygous TA1160 subNIL lines and 2 controls (TA209 and TA1160) were transplanted to the field on May 31,2001 . For both series of subNILs a complete random block experimental design was used, thus a single plant for each line was randomly assigned a position within each block, and seven blocks of the subNILs 
Table 2. Means and standard deviations of quantitative traits for TA1160 and TA209 traits with asterisks $\left(^{*}\right)$ are significantly different (p-value $<0.05$ )

\begin{tabular}{|c|c|c|c|c|c|c|c|c|c|}
\hline \multirow[t]{3}{*}{ Category } & \multirow{3}{*}{$\begin{array}{l}\text { Trait } \\
\text { measured }\end{array}$} & \multicolumn{4}{|c|}{ New York } & \multicolumn{4}{|c|}{ California } \\
\hline & & \multicolumn{2}{|l|}{ TA209 } & \multicolumn{2}{|c|}{ TA1138 } & \multicolumn{2}{|c|}{ TA209 } & \multicolumn{2}{|l|}{ TA1138 } \\
\hline & & Mean & st dev & Mean & st dev & Mean & st dev & Mean & st dev \\
\hline \multirow[t]{6}{*}{ Fruit color } & External color & 3.2 & 0.4 & 3.0 & 0.5 & 3.2 & 0.6 & 3.0 & 0.0 \\
\hline & Internal color & 2.8 & 0.6 & 3.0 & 0.6 & 3.0 & 0.4 & 3.0 & 0.0 \\
\hline & Lycopene & nd & nd & nd & nd & $89.9^{*}$ & 6.6 & $100.8^{*}$ & 2.7 \\
\hline & Hue & nd & nd & nd & nd & $2.36^{*}$ & 1.1 & $22.2^{*}$ & 0.2 \\
\hline & Chroma & nd & nd & nd & nd & 13.1 & 0.8 & 14.0 & 0.3 \\
\hline & $\mathrm{A} / \mathrm{b}$ & nd & nd & nd & nd & 2.3 & 0.1 & 2.5 & 0.0 \\
\hline \multirow[t]{8}{*}{ Fruit quality } & Fruit weight & $81.5^{*}$ & 10.9 & $66.9^{*}$ & 12.5 & 71.5 & 3.5 & 68.5 & 0.5 \\
\hline & Stem scar & $3.2^{*}$ & 0.7 & $2.5^{*}$ & 0.5 & $3.7^{*}$ & 0.5 & $3.0^{*}$ & 0.0 \\
\hline & Cracks & 2.0 & 0.6 & 1.9 & 0.6 & 2.0 & 0.7 & 2.0 & 0.0 \\
\hline & Firmness & 3.0 & 0.4 & 2.7 & 0.7 & 2.8 & 0.6 & 3.3 & 0.6 \\
\hline & Shape & $3.1^{*}$ & 0.5 & $2.2^{*}$ & 0.6 & 2.0 & 0.0 & 2.0 & 0.0 \\
\hline & Reticulation & $1.0^{*}$ & 0.2 & $2.5^{*}$ & 0.5 & $1.2^{*}$ & 0.4 & $2.3^{*}$ & 0.6 \\
\hline & Wall & $3.4^{*}$ & 0.7 & $2.6^{*}$ & 0.6 & nd & nd & nd & nd \\
\hline & Puffy & $1.8^{*}$ & 0.7 & $1.0^{*}$ & 0.2 & 2.3 & 0.6 & 1.7 & 0.6 \\
\hline \multirow[t]{8}{*}{ Processing quality } & Brix & $5.6^{*}$ & 0.5 & $6.0^{*}$ & 0.8 & $5.0^{*}$ & 0.2 & $5.9^{*}$ & 0.4 \\
\hline & $\mathrm{PH}$ & nd & nd & nd & nd & 4.4 & 0.1 & 4.3 & 0.1 \\
\hline & Total organic acids (TOA) & nd & nd & nd & nd & $23.7^{*}$ & 2.0 & $26.3^{*}$ & 0.4 \\
\hline & Titratable acids & nd & nd & nd & nd & $4.9^{*}$ & 0.4 & $5.4^{*}$ & 0.2 \\
\hline & Sugar/acid ratio (SAR) & nd & nd & nd & nd & $5.6^{*}$ & 0.4 & $4.8^{*}$ & 0.6 \\
\hline & Juice Bostwick & nd & nd & nd & nd & 18.9 & 1.6 & 17.9 & 1.3 \\
\hline & Paste Bostwick & nd & nd & nd & nd & 6.0 & 1.5 & 5.1 & 1.3 \\
\hline & Ostwald & nd & nd & nd & nd & 298.2 & 95.9 & 369.8 & 17.6 \\
\hline \multirow[t]{3}{*}{ Agronomic quality } & yield potential & nd & nd & nd & nd & 3.3 & 0.5 & 3.0 & 0.0 \\
\hline & lstred & nd & nd & nd & nd & 36.1 & 5.1 & 41.0 & 0.0 \\
\hline & brix $\times$ yield potential & nd & nd & nd & nd & 16.7 & 2.3 & 17.6 & 1.1 \\
\hline
\end{tabular}

were transplanted. Each control was randomly assigned four places within each block. Trait evaluations were made in early August in CA and late September in NY.

\section{Trait evaluations}

The 34 and 10 traits measured in CA and NY, respectively, for the TA1138 subNILs are listed in Table 1. The 24 and 11 traits measured in CA and NY, respectively, for the TA1160 subNILs are listed in Table 2. For a full description of the traits and how they were measured, see Tanksley et al. (1996) and Frary et al. (2002). Details of traits not covered in either paper are given below.

Fruit quality: Ten ripe fruit per plot were evaluated in CA, and five ripe fruit per plant were evaluated in NY. Fruit shape was evaluated for TA1160 only, as TA1138 had been determined to have fruit with a shape similar to the recurrent parent TA209. In CA, fruit was visually scored as 1 (round) to 5 (elongated). In NY, fruit were scored for an 'egg shape,' which was a slightly elongated fruit with no indentation around the stem scar, with the scale of 1 (no indentation at stem scar, i.e. no 'shoulder') to 5 (deep indentation at stem scar, i.e. high 'shoulder'). Epidermal reticulation (ER), which is the corky appearance of the skin, was scored for TA1160 in both NY and CA on a scale of 1 (no reticulation, smooth skin) to 5 (very reticulated, corky, like a cantaloupe melon). TA1138 was scored for reticulation in NY on a scale of 1 (no reticulation, smooth skin) to 9 (very reticulated). In CA however, TA1138 fruit skin was scored for 'dullness' (dull) on a scale of 1 (very smooth and bright, i.e. less dull) to 9 (very dull and rough). Pericarp thickness (wall) was determined for transversely cut fruit and scored 
visually on a scale of 1 (thin pericarp) to 5 (thick pericarp) for TA1160 (visual score in NY only) and 1 (thin pericarp) to 9 (thick pericarp) for TA1138.

Processing quality: Mono-sodium glutamate (MSG) was measured using a Sigma Glutamate Analysis Kit (cat\# GLN1). Ten micro-liters of tomato serum were analyzed in duplicate for each sample per kit instructions using a Cary 100 spectrophotometer. For sugar measurements, five grams of sample were extracted with $20 \mathrm{ml}$ of ethanol. The supernatant was then analyzed by HPLC using a refractive index detector. Beta-Carotene was measured by Agilent 1050 HPLC using a $\mathrm{C} 18$ column. Vitamin A was calculated based on the carotenoid content of the sample. Titratable acids (TA) were titrated using $0.1 \mathrm{~N}$ sodium hydroxide using a Mettler DL67 fitted with a ST20A Sample Changer. Estimated Total Organic Acids (TOA) was measured during the titration of the sample.

Agronomic quality: Plots in CA were also scored for the appearance of the first red fruit measured in number of days past June 1 ( $1^{\text {st }}$ red). For the TA1138 plots in CA only, at the time of harvest a single plant was shaken to remove fruit, which were then sorted according to green fruit and red fruit. Red fruit was scored visually for fruit uniformity (i.e. size, shape, general aesthetics) on a scale of 1 (not uniform, much variation between fruit) to 9 (very uniform, no variation). Additionally, red fruit was divided into those with stems and those without. These measurements were subsequently used to estimate the percentage of ripe fruit (\% red), as well as the percentage of ripe fruit retaining stems (\% stem).

\section{Data analysis}

Homozygous TA1160 and TA1138 and their corresponding subNILs were compared to the L. esculentum cv E6203 (TA209) control for each trait's phenotypic values with t-tests at $p \leq 0.05$ using the Statview software package for Macintosh (SAS Institute Inc.). NILs and subNILs which differed from the TA209 control $(p \leq 0.05)$ were considered to carry the wild species allele at a locus (loci) controlling the corresponding trait. The genomic region included in a subNIL was considered to be harboring a QTL for that trait when the mean for a particular trait showed a highly significant difference between that subNIL and the TA209 control. Confirmation was provided when this difference was consistent for the same line in both locations and for other lines containing similar introgressions. Only QTL that were confirmed in this way are included in the summary figure (Figure 4). When several subNILs showed the same effect, the QTL was localized to the smallest chromosomal region shared by all of those subNILs.

\section{Results and discussion}

\section{Evaluation of TA1138 and TA1160 NILs relative to the L. esculentum TA209 control}

Tables 1 and 2 summarize the results of the field evaluations of both the elite processing control (TA209) and the TA1138 and TA1160 NILs, respectively.

TA1138: The TA1138 NIL produced fruit significantly reduced in weight, but with increased brix values, in both CA and NY. In the NY trial, TA1138 had a significantly smaller stem scar, firmer fruit, and better external color than TA209. In CA, TA1138 was found to have a 'duller' epidermis, greater fruit uniformity, more vegetative cover, more acids, lower sugar to acid ratio, lower glutamate, higher total sugars, greater viscosity (i.e. lower Juice Bostwick) and less separation of water from the processed product (Ostwald) (Table 1).

TA1160: Compared to the TA209 control, the TA1160 NIL showed a significant increase in soluble solids (brix), as well as reduced stem scar, but also more epidermal reticulation in both the CA and NY locations. In the NY trial, TA1160 had lower fruit weight, less puffiness, and a thinner pericarp than TA209. While visual color ratings were not significantly different in either location, the lab tests performed in CA showed that TA1160 had more lycopene, a higher $\mathrm{A} / \mathrm{B}$ score, and reduced hue. In addition, in NY a shape trait was scored, and TA1160 was more 'egg-shaped', with shallower shoulders than TA209. In CA, TA1160 was found to have increased acid content and a lower sugar to acid ratio compared to TA209 (Table 2).

The above results demonstrate that the TA1160 and TA1138 chromosome 4 introgressions affect a wide variety of traits, and that many of the effects are common to both TA1138 and TA1160. This raises the question of whether multiple linked genes on each introgression specify different traits, or alternatively, that one or two genes manifest pleiotropic effects. 

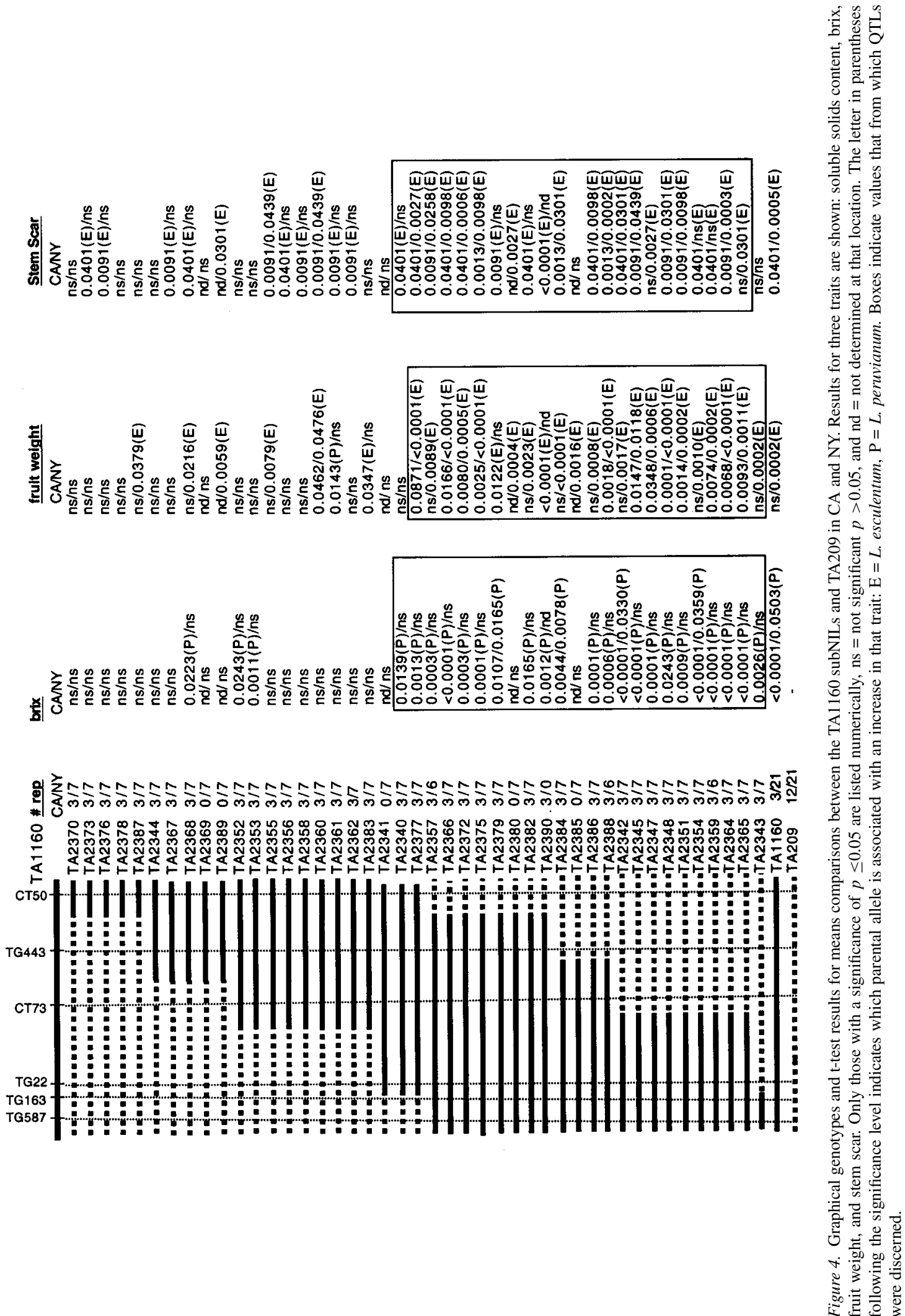
Additionally, when a given trait is affected by both introgressions, is this due to allelic or non-allelic variation. In an effort to address these questions, we have generated and evaluated a set of subNILs for both TA1138 and TA1160.

\section{Evaluation of subNILs for fine mapping of QTLs}

A selected subset of traits for which the TA1160 and TA1138 NILs differed from the controls was selected for examination in the corresponding subNILs. For both TA1138 and TA1160 subNILs, T-tests were used to determine which of the individual subNILs differed significantly from the L. esculentum control (TA209). By grouping subNILs according to their genotype, QTLs were localized to the smallest overlapping regions in which the p-values differentiated significantly from the control for that particular trait (Figures 2-5).

\section{Mapping of QTLs in the TA1138 introgression using subNIL data}

Brix: SubNILs containing the top and/or central region of the L. hirsutum chromosome 4 introgression consistently had significantly higher brix values than the TA209 control, while those without this region were rarely significantly different from TA209 (Figure 2). By considering the overlapping regions of the significant subNILs, it appears that there are two regions associated with the increased soluble solids from L. hirsutum. The primary QTL is in the $6 \mathrm{cM}$ region between TG555 and T769, as indicated by subNIL TA3177, and another secondary QTL in the $4 \mathrm{cM}$ region between TG62 and TG65 (Figure 2). This result is consistent with previous studies (Bernacchi et al., 1998a). Monforte et al. (2001) also found a QTL for soluble solids content in the $18 \mathrm{cM}$ region between TG155 and CT50, and this study more precisely maps that QTL. This study supports the two locus hypothesis and provides much better resolution of these brix loci.

Fruit weight: The subNILs containing the $4 \mathrm{cM}$ region from TG62 to TG65 had significantly reduced fruit size compared to TA209 indicating a primary QTL in this region (Figure 2). Additionally, a minor QTL for fruit weight was localized to the $15 \mathrm{cM}$ region between T769 and CT50. This result concurs with the results of Monforte et al. (2001), which placed the QTL in the same $18 \mathrm{cM}$ region as the soluble solids QTL. Bernacchi et al. (1998a) also found this overall region of chromosome 4 to have reduced fruit weight, but was unable to localize a QTL. While some of the subNILs containing this $15 \mathrm{cM}$ region do not have significantly reduced fruit weight, this study indicates the presence of such a QTL.

Stem scar: Figure 2 also shows that subNILs with the top $4 \mathrm{cM}$ between TG62 and TG65 have a significantly reduced stem scar compared to the control for the NY data. While other subNILs outside of this $4 \mathrm{cM}$ region show significantly reduced stem scar size, this region shows both the greatest significance as well as the most consistency. It is possible there is a second QTL in this lower region, however a definitive QTL could not be localized.

Acid, glutamate and sugars: Most subNILs containing the top $4 \mathrm{cM}$ of the introgression (TG62 to TG65) showed increased total organic acids (TOA) as well as increased total titratable acids (TA), while none without the top were significant, suggesting that there is an acid QTL in this region (Figure 3). Additionally, most subNILs containing the top $4 \mathrm{cM}$ of the introgression also show decreased glutamate (MSG). This is consistent with the finding of Fulton et al. (2002) which place a glutamic acid locus and a total acids QTL in the 9cM region between TG62 and TG65. Also subNILs containing the 4cM region between TG62 and TG65 show increased total sugars.Again, there are some subNILs outside of this region that show significance indicating the possibility of a second QTL, but not in a consistent pattern that could discern such a QTL (Figure 3).

Additional traits identified in previous studies: The TA1138 NIL was found to be significantly different from TA209 for other traits, and other studies have localized QTLs for firmness, viscosity, color, red yield and brix red yield to this region (Bernacchi et al., 1998a; Monforte et al., 2001). Several subNILs were significantly different from TA209 for these traits; however, there was not a discernable pattern that would allow specific loci to be fine mapped (data not shown). Environmental influences may account for these results, but we can not rule out the possibility that the effects are due to multiple loci whose individual effects could not be discerned via the subNIL approach applied here. 

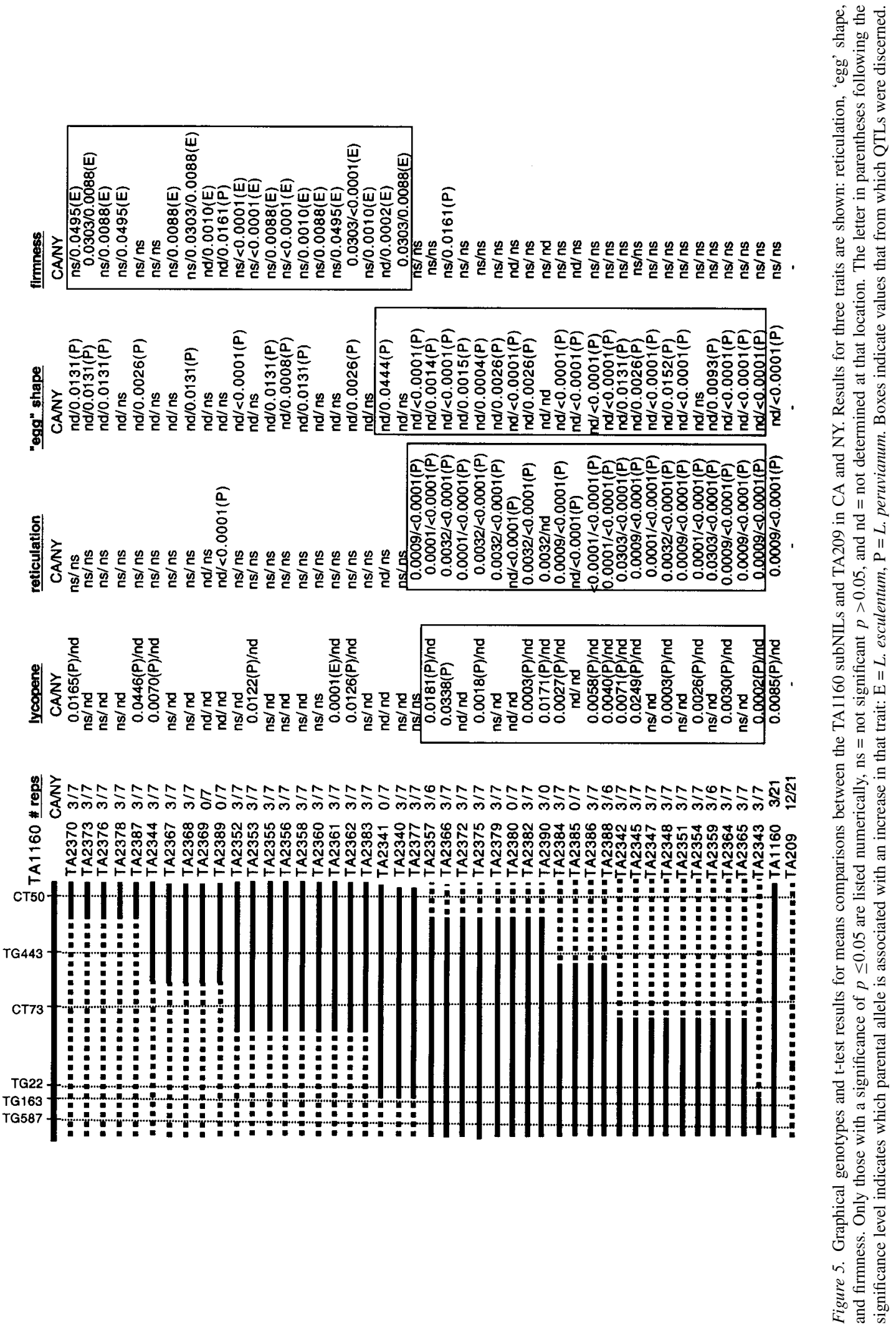
Mapping of QTLs in the TA1 160 introgression using subNIL data

Brix, fruit weight, and stem scar: Figure 4 shows that the subNILs containing the $3 \mathrm{cM}$ section of the introgression between TG22 and TG587 have significantly higher soluble solids content (brix) than the control, particularly in the CA data. SubNILs containing the same $3 \mathrm{cM}$ region also have decreased fruit weight and reduced stem scar, indicating QTLs for all three traits in this region (Figure 4).

Reticulation, shape, and lycopene: SubNILs containing the same $3 \mathrm{cM}$ region, as described above, also have increased epidermal reticulation, more 'egg shaped' fruit, and greater lycopene than TA209 (Figure 5). These results are consistent with the findings of Monforte et al. (2001), but provide greater resolution. Also, these results suggest that there may be a single gene influencing all of these traits, or multiple genes that are tightly linked in this region.

Firmness: Despite the fact that TA1160 and the TA209 control did not differ in fruit firmness, subNILs containing the $7 \mathrm{cM}$ region at the top of the introgression (CT50 to CT73) have significantly decreased firmness in the NY data (Figure 5). However, this effect was not observed in CA.

Additional traits identified in previous studies: Monforte et al. (2001) also found that TA1160 enhanced color (both internal and external) as well as decreased yield. However, other than lycopene, this study did not find the color traits to be significantly different from the TA209 control for the individual subNILs (data not shown).

\section{Implications of QTL fine mapping for breaking linkage drag}

TA1138: The analysis of the TA1138 subNILs show separate linked loci for fruit weight and for brix (Figure 1). This suggests it is possible to create a subNIL containing the favorable characteristic of increased soluble solids with little or no reduction in fruit weight, by selecting for those subNILs which have a recombination between T688 and TG574, separating the primary brix loci from the primary fruit weight loci (Figure 2). For example, the subNIL TA2618 (which has increased brix but not decreased fruit weight) may have retained the primary brix QTL but remains unaffected by the secondary fruit weight loci. Also, TA3177 (which is the smallest subNIL containing the central brix locus) can be further broken into sub-subNILs to break the brix from the fruit weight, and provide a small introgressed segment for marker assisted breeding.

The top of the introgression (TG62 to TG65) is also of interest. The co-localization of brix, fruit weight, scar, glutamate, and acids may indicate that these traits are controlled by a single locus with pleiotropic effects (Figure 1). A more in-depth look at subNIL TA2653 (which has the increased brix but not the decreased fruit weight) may help to determine whether the traits are the effects of pleiotropy or closely linked loci.

Further experimentation may be considered to determine if there are in fact firmness, viscosity and yield QTLs within this region, as indicated by previous studies, even though the lab data that was collected for this study yielded no discernable QTLs (Bernacchi et al., 1998a; Monforte et al., 2001).

TA1160: The analysis of the TA1160 subNILs shows a co-localization of four traits to the $3 \mathrm{cM}$ region between TG22 and TG587 (Figure 5). While it is possible that there are separate, but tightly linked, genes controlling these traits, we can not rule out the possibility that the traits are the effects of pleiotropy particularly for physiologically related traits. For example, the gene that controls soluble solids content may also control fruit weight, as the sugar production for a large fruit could be a strain on the plant's resources, thus favoring smaller fruit. A difficulty with this study was the lack of subNILs with a recombination below TG163. Finer mapping of this region of chromosome 4 (below TG22) will be necessary to determine if the beneficial traits can be separated from the detrimental ones. Creating smaller subNILs from TA2343 may provide insight into a solution for this problem.

\section{Non-allelic genes controlling same traits in the TA1138 and TA1160 NILs}

While TA1138 and TA1160 both show discernable loci for stem scar, fruit weight, and brix, these QTLs are non-allelic between the two introgressions (Figure 1). The two brix QTLs localized in the TA1138 subNILs are found above the region of overlap with TA1160, while the brix QTL found in the TA1160 subNILs was found below the overlapping region with TA1138 (Figure 1). The same is true for both the fruit 
weight and stem scar QTLs that were localized for each set of subNILs. Additionally, the reduced firmness QTL found on the TA1160 introgression was not detected in the TA1138 subNILs although it is in the region that the NILs overlap. All shared traits were thus found to be non-allelic between the two species introgressions.

\section{Implications for creating chimeric introgressions with novel performance}

As the QTLs for soluble solids are in different regions of the introgression for the L. hirsutum NIL (TG 62 to T292 and TG555 to T769) and the L. peruvianum NIL (TG22 to TG163), it would be possible to combine the brix QTLs from these two species through cis recombination. For example, recombining the TA1138 subNIL TA2618 with the TA1160 subNIL TA2343 through a crossover in the T708 to TG22 interval would result in a chimeric chromosome 4 that would have brix QTLs from both L. hirsutum and $L$. peruvianum (Figure 1). Alternatively, a recombination of the TA1138 subNILs TA2618 and TA2653 through a crossover in theTG65 to TG555 interval, followed by a recombination with the TA1160 subNIL TA2343 through a crossover in theT708 to TG22 interval would result in a chimeric chromosome 4 with all three brix loci in this region (two from L. hirsutum and one from $L$. peruvianum). If additive in nature, such a recombination could show novel performance in the soluble solids content. Such a combination of subNILs would also retain the favorable traits of reduced stem scar, decreased glutamate, increased total organic acids, and increased total sugars from L. hirsutum, as well as the 'egg' shaped fruit and reduced stem scar of L. peruvianum. However, one must consider that the L. peruvianum introgression would retain the effects of reduced fruit size and epidermal reticulation.

\section{Conclusion}

The long arm of chromosome 4 of tomato has been shown to harbor QTLs for several interesting phenotypic traits. Fine mapping of these QTLs using sets of overlapping recombinant lines (subNILs) generated from two wild species NILs, TA1138 from L. hirsutum and TA1160 from L. peruvianum, found QTLs for soluble solids content (brix), fruit weight, and stem scar size to be non-allelic. Additional QTLs for glutamate, total sugars, and total organic acids were localized on the TA1138 NIL, and QTLs for firmness, epidermal reticulation, "egg' shape, and lycopene were localized on the TA1160 NIL. Further isolation of recombinants of the TA1160 subNIL TA2343 should help to determine if the loci controlling some traits (e.g. fruit shape, fruit weight, and epidermal reticulation) may be attributed to pleiotropy or to gene-dense areas with lower than average recombination. The non-allelic nature of the soluble solids loci suggest that it may be possible to combine the $L$. hirsutum and $L$. peruvianum alleles in a single line with the potential for extremely high soluble solids.

\section{Acknowledgements}

This project was supported by grants from the USDA National Research Initiative Cooperative Grants Program (No.9600558), The Binational Agricultural Research and Development Fund (No. IS-3009-98C), and by funding from Seminis Vegetable Seeds.

\section{References}

Bernacchi, D., T. Beck-Bunn, Y. Eshed, J. Lopez, V. Petriard, J. Uhlig, D. Zamir \& S. Tanksley, 1998a. Advanced backcross QTL analysis in tomato. I. Identification of QTLs for traits of agronomic importance from L. hirsutum. Theor Appl Genet 97: 381-397.

Bernacchi, D., T. Beck-Bunn, D. Emmatty, Y. Eshed, S. Inai, J. Lopez, V. Petriard, H. Sayama, J. Uhlig, D. Zamir \& S. Tanksley, 1998b. Advanced backcross QTL analysis in tomato. II. Evaluation of near-isogenic lines carrying single-donor introgressions for desirable QTL-alleles derived from L. hirsutum and L. pimpinellifolium. Theor Appl Genet 97: 170-180.

de Vincente, M.C. \& S.D. Tanksley, 1993. QTL analysis of transgressive segregation in an interspecific tomato cross. Genetics 134: 585-596.

Eshed, Y. \& D. Zamir, 1995. An introgression line population of Lycopersicon pennellii in the cultivated tomato enables the identification and fine mapping of yield-associate QTLs. Genetics 141: 1147-1162.

Foolad, M.R., L.P. Zhang, A.A. Khan, D. Nino-Liu \& G.Y. Lin, 2002. Identification of QTLs for early blight, Alternaria solani resistance in tomato using backcross populations of a Lycopersicon esculentum $\times$ L. hirsutum cross. Theor Appl Genet 104: 945-958.

Frary, A., S. Doganlar, A. Frampton, T.M. Fulton, J. Uhlig, H.E. Yates \& S.D. Tanksley, 2002. Fine Mapping of quantitative trait loci for improved fruit characteristics from Lycopersicon chmielewskii chromosome 1. Genome, in press.

Fulton, T.M., T. Beck-Bunn, D. Emmatty, Y. Eshed, J. Lopez, V. Petriard, J. Uhlig, D. Zamir \& S.D. Tanksley, 1997a. QTL analysis of an advanced backcross of Lycopersicon peruvianum to the cultivated tomato and comparisons with QTLs found in other wild species. Theor Appl Genet 95: 881-894. 
Fulton, T.M., J.C. Nelson \& S.D. Tanksley, 1997b. Introgression and DNA marker analysis of Lycopersicon peruvianum, a wild relative of the cultivated tomato, into Lycopersicon esculentum, followed through three successive backcross generations. Theor Appl Genet 95: 895-902.

Fulton, T.M., S. Grandillo, T. Beck-Bunn, E. Fridman, A. Frampton, J. Lopez, V. Petriard, J. Uhlig, D. Zamir \& S.D. Tanksley, 2000. Advanced backcross QTL analysis of a Lycopersicon esculentum $\times$ Lycopersicon parviflorum cross. Theor Appl Genet 100: 1025-1042.

Fulton, T.M., P. Bucheli, E. Voirol, V. Petriard \& S.D. Tanksley, 2002. Quantitative trait loci, QTL affecting sugars, organic acids and other biochemical properties possibly contributing to flavor, identified in four advanced backcross populations of tomato. Euphytica 127: 163-177.

Kosambi, D.D., 1944. The estimation og map distance from recombination values. Ann Eugen 12: 172-175.

Lander, E.S., P. Green, J. Abrahamson, A. Barlow, M.J. Daly, S.E. Lincoln \& L. Newburg, 1987. MAPAMAKER: an interactive computer package for constructing primary genetic linkage maps of experimental and natural populations. Genomics 1: 174-181.

Levin, I., N. Gilboa, E. Yeselson, S. Shen, A.A. Schaffer, 2000. $F g r$, a major locus that modulates the fructose to glucose ratio in mature tomato fruits. Theor Appl Genet 100: 256-262.
Miller, J.C. \& S.D. Tanksley, 1990. RFLP analysis of phylogenetic relationships and genetic variation in the genus Lycopersicon. Theor Appl Genet 80: 437-310.

Monforte, A.J., E. Friedman, D. Zamir \& S.D. Tanksley, 2001. Comparison of a set of allelic QTL -NILs for chromosome 4 of tomato: Deductions about natural variation and implications for germplasm utilization. Theor Appl Genet 102: 572-590.

Tanksley, S.D., M.W. Ganal, J.P. Prince, M.C. deVicente, M.W. Bonierbale, P. Broun, T.M. Fulton, J.J. Giovannoni, S. Grandillo, G.B. Martin, R. Messeguer, J.C. Miller, A.H. Paterson, O. Pineda, M.S. Roder, R.A. Wing, W. Wu \& N.D. Young, 1992. High density molecular linkage map of the tomato and potato genomes. Genetics 132: 1141-1160.

Tanksley, S.D. \& J.C. Nelson, 1996. Advanced backcross QTL analysis: a method for the simultaneous discovery and transfer of valuable QTLs from unadapted germplasm into elite breeding lines. Theor Appl Genet 92: 191-203.

Tanksley, S.D., S. Grandillo, T.M. Fulton, D. Zamir, Y. Eshed, V. Petriard, J. Lopez \& T. Beck-Bunn, 1996. Advanced Backcross QTL analysis in a cross between an elite processing line of tomato and its wild relative L. pimpinellifolium. Theor Appl Genet 92: 213-224.

Tanksley, S.D. \& S.R. McCouch, 1997. Seed banks and molecular maps: unlocking genetic potential from the wild. Science 277 : 1063-1066. 